\title{
CARACTERIZAÇÃo POTENCIOMÉTRICA E RECONHECIMENTO DE PADRÕES DE ÁCIDOS HÚMICOS EXTRAÍDOS DE SOLOS DE ALTITUDE
}

\author{
Rita Aparecida Dutra ${ }^{1}$, Efraim Lázaro Reis ${ }^{1 *}$, Vinícius de Mello Benites ${ }^{2}$, César Reis ${ }^{1}$, Clausius Duque Gonçalves Reis ${ }^{3}$, \\ Eduardo de Sá Mendonça ${ }^{4}$, Paulo Henrique Fidêncio ${ }^{5}$ \\ ${ }^{1}$ Departamento de Química, Universidade Federal de Viçosa, 36.570-900, Viçosa, MG \\ ${ }^{2}$ Embrapa Solos, Jardim Botânico, 22.460-000 - Rio de Janeiro - RJ \\ ${ }^{3}$ Instituto de Ciências Exatas, Universidade Federal de Viçosa, 38.810-000, Rio Paranaíba, MG \\ ${ }^{4}$ Departamento de Agronomia, Universidade Federal do Espírito Santo, 29.500-000, Alegre, ES \\ ${ }^{5}$ Departamento de Química, Universidade Federal dos Vales do Jequitinhonha e Mucurí, 39.100-000, Diamantina, MG
}

*E-mail: efraimreis@gmail.com

\section{RESUMO}

A vegetação de altitude encontrada no topo das montanhas mais altas do Brasil, como os complexos Espinhaço e Mantiqueira, nos estados de Minas Gerais e Bahia, consiste em ecossistemas com características marcantes na diversidade da flora e fauna. O solo nessas áreas é geralmente raso, pobre em nutrientes, mas rico em ferro e alumínio trocáveis. A caracterização dos ácidos húmicos de tais ecossistemas entre outros componentes químicos é muito útil para entender as propriedades fundamentais da composição orgânica do solo. Foram caracterizados potenciometricamente um total de 72 amostras de solo de 10 locais distintos nos complexos Espinhaço e Mantiqueira. Os dados das titulações potenciométricas foram processados em um software baseado na linguagem Delphi, a fim de obter as constantes de ionização e as porcentagens dos grupos titulados. Este software demonstrou ser eficiente na reprodução das curvas de titulação com uma concordância notável às experimentais. Após o processamento dos dados potenciométricos, os valores das constantes de ionização e porcentagens dos grupos carboxílicos e fenólicos foram submetidos à análise das componentes principais no ambiente MatLab, utilizando uma matriz de 72 amostras e 10 variáveis, obtendo um modelo em que se constatou que as quatro primeiras componentes principais explicavam $91,23 \%$ da variação total dos dados originais. A análise das componentes principais mostrou uma separação relativa entre as amostras. As características dos ácidos húmicos evidenciadas pelas titulações potenciométricas refletem as condições em que estes ácidos foram formados, embora não permitindo uma separação mais eficaz entre os grupos evidenciados pela análise das componentes principais.

Palavras-chave: Solos de altitude. Ácidos húmicos. Titulação potenciométricas. Análise das componentes principais.

\section{Introdução}

A matéria orgânica presente em solos, turfas e sedimentos consiste em uma mistura de produtos, em vários estágios de decomposição, resultantes da degradação química e biológica de resíduos vegetais e animais, e da atividade de síntese de microorganismos. Esta mistura é conhecida como húmus e se divide em substâncias não húmicas e húmicas, em que as substâncias não húmicas são de natureza definida como aminoácidos, proteínas, etc., ao passo que as substâncias húmicas são de estrutura química complexa, compondo um grupo de compostos heterogêneos [1].

As substâncias húmicas são formadas a partir de inúmeros mecanismos e rotas bioquímicas, que atuam de acordo com a qualidade do substrato orgânico e as condições químicas do meio onde são processadas essas reações [2].

A caracterização de substâncias húmicas é um instrumento de grande utilidade para o conhecimento das propriedades fundamentais do sistema orgânico do solo. Os dados obtidos podem ser aplicados ao estudo das interações existentes entre fração orgânica e inorgânica do solo, influência de clima, solo e vegetação na formação de substâncias húmicas, processos de humificação, atuação de substâncias húmicas como controladores de funções fisiológicas dos organismos vivos, fertilidade do solo, microbiologia do solo, efeitos geoquímicos e outros [3]. 
Na figura 1 é apresentada uma proposta de estrutura macromolecular do ácido húmico [4].

A determinação das substâncias húmicas pode ser feita por titulação potenciométrica, a fim de distinguir diferentes grupos funcionais como os carboxílicos e fenólicos. A curva de titulação potenciométrica é obtida a partir do $\mathrm{pH}$ medido no decorrer da titulação em função do volume de solução de hidróxido de sódio adicionado.

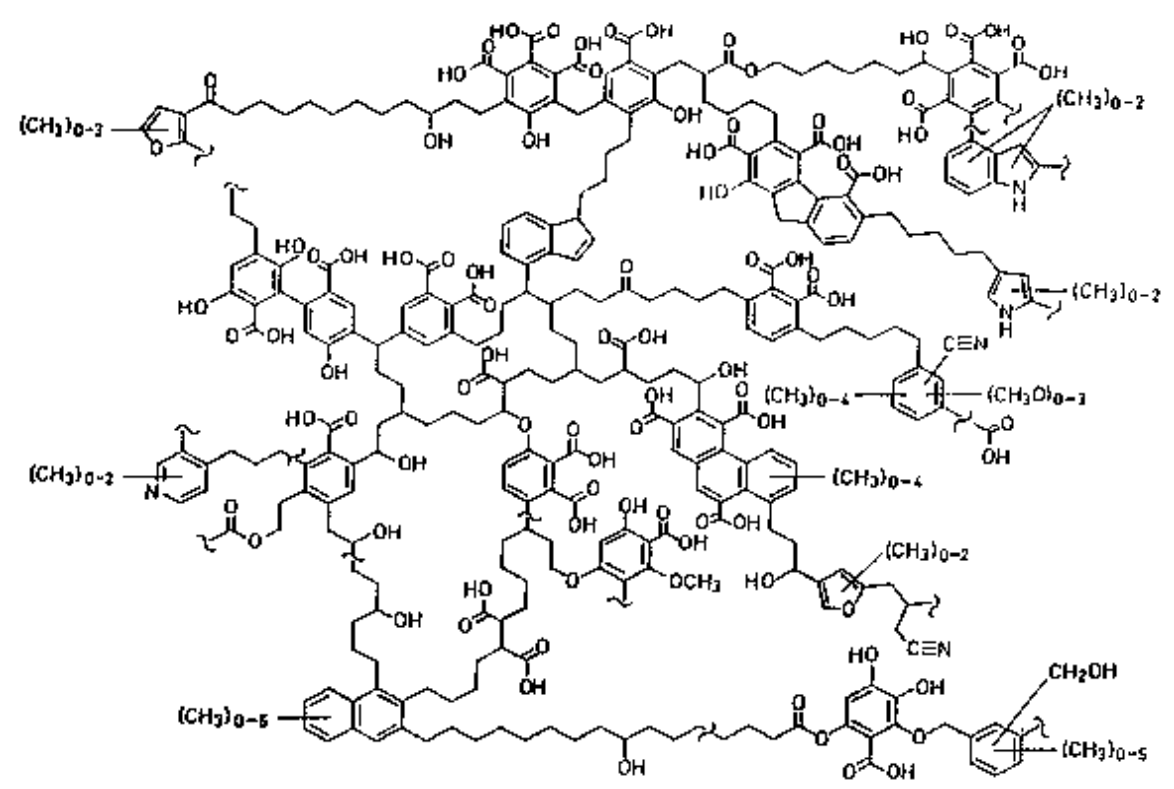

Figura 1. Esquema da estrutura macromolecular do ácido húmico proposta por Schulten \& Schnitzer [4].

Segundo Lindberg \& Kowalski [5], na avaliação dos dados da titulação de multicomponentes, a não individualidade de cada ponto de inflexão na curva de titulação é um fator que governa a precisão de predição. A intensidade no qual ocorrem os pontos de inflexão é dada pelas diferenças entre os valores de $\mathrm{pK}_{\mathrm{a}}$ dos ácidos nas misturas. De maneira que as informações que diferenciam os ácidos no meio estão localizadas em volta de seus valores de $\mathrm{pK}_{\mathrm{a}}$ ao passo que os pontos de inflexão contém informações em termos da soma total de ácidos na amostra. Mas, para eletrólitos fracos em soluções diluídas, as curvas de titulação não apresentam pontos de inflexão bem definidos, tornando-se impossível a aplicação do método da segunda derivada para determinar o ponto final da titulação.

Assim os respectivos valores das constantes de ionização dos ácidos $\left(\mathrm{pK}_{\mathrm{a}}\right)$ podem ser determinados, aplicando uma metodologia no qual os pontos de inflexão em uma curva de titulação que não são observáveis, tornem-se evidentes identificando os respectivos $\mathrm{pK}_{\mathrm{a}}$ dos ácidos. A possibilidade explorada é o método de regressão multiparamétrica não-linear para o tratamento dos dados da titulação potenciométrica de substâncias húmicas em meio aquoso, para diferenciar os grupos ácidos, permitindo a determinação das concentrações e dos valores de $\mathrm{pK}_{\mathrm{a}}$ de cada grupo titulável presente nos ácidos húmicos [6].

Objetivou-se neste trabalho, caracterizar potenciometricamente os grupos ácidos presentes nos ácidos húmicos, para observar relações entre as características das amostras de solos e as condições pedoambientais de origem. Para isto foi utilizado um programa computacional para efetuar o ajuste multiparamétrico para determinar os parâmetros tais como constantes de ionização e porcentagens de grupos funcionais [6].

Posteriormente utilizou-se a análise das componentes principais que permitiu definir através de visualizações gráficas do conjunto de dados, as relações entre as características das amostras e as condições pedoambientais de origem.

\section{Parte Experimental}

As amostras de solo foram coletadas em horizontes superficiais e em horizontes subsuperficiais, de forma a representar os principais solos de áreas de vegetação rupestre de altitude na Serra do Espinhaço e na Serra da Mantiqueira, em Minas Gerais e Bahia. Todas as amostras foram obtidas em unidades de conservação entre parques nacionais e estaduais, áreas de proteção ambiental e reservas particulares (Tabela 1). 


\subsection{Preparo de soluções}

- Solução de ácido clorídrico aproximadamente $0,1 \mathrm{~mol} \mathrm{~L}^{-1} \mathrm{em}$ $\mathrm{NaCl} \quad 0,1$ mol L $\mathrm{L}^{-1}$. Solubilizou-se $5,844 \mathrm{~g}$ de $\mathrm{NaCl}$ (MERCK) em aproximadamente $300 \mathrm{~mL}$ de água deionizada, em seguida adicionou-se $6,22 \mathrm{~mL}$ de $\mathrm{HCl}$ (VETEC) $36,5 \% \mathrm{~m} / \mathrm{m}$ e completou-se o volume para $1000 \mathrm{~mL}$ em balão volumétrico.

- Solução de hidróxido de sódio aproximadamente $0,1 \mathrm{~mol} \mathrm{~L}^{-1}$ em $\mathrm{NaCl} 0,1 \mathrm{~mol} \mathrm{~L}^{-1}$. Solubilizou-se $4,0 \mathrm{~g}$ de $\mathrm{NaOH}$ (MERCK) em aproximadamente $200 \mathrm{~mL}$ de água deionizada, acrescentou-se $5,844 \mathrm{~g}$ de $\mathrm{NaCl}$ (MERCK) solubilizada em $200 \mathrm{~mL}$ de água deionizada e completou-se o volume para $1000 \mathrm{~mL}$ em balão volumétrico.
- Padronização da solução de $\mathrm{NaOH}$ com biftalato de potássio. Pesou-se 0,250 g de $\mathrm{C}_{8} \mathrm{H}_{5} \mathrm{O}_{4} \mathrm{~K}$ (previamente seco em estufa a $100{ }^{\circ} \mathrm{C}$ por uma hora) em balança analítica dissolvendo-se em $25 \mathrm{~mL}$ de solução de $\mathrm{NaCl} 0,1 \mathrm{~mol} \mathrm{~L}^{-1}$. Iniciou-se a titulação potenciométrica, adicionando a solução de $\mathrm{NaOH}$ com incremento de $0,2 \mathrm{~mL}$ até $25 \mathrm{~mL}$.

- $\quad$ Padronização da solução de $\mathrm{HCl}$ com carbonato de sódio.

Pesou-se 0,106 g de $\mathrm{Na}_{2} \mathrm{CO}_{3}$ (previamente seco em estufa a $100{ }^{\circ} \mathrm{C}$ por uma hora) em balança analítica. Esta massa foi dissolvida em $25 \mathrm{~mL}$ de solução de $\mathrm{NaCl} \quad 0,1 \mathrm{~mol} \mathrm{~L}^{-1}$. Iniciou-se a titulação potenciométrica adicionando a solução de $\mathrm{HCl}$ com incremento de $0,3 \mathrm{~mL}$ até $30 \mathrm{~mL}$.

Os ácidos húmicos foram extraídos e purificados segundo o método sugerido por Benites e colaboradores [7].

Tabela 1. Unidades de conservação, município sede, serra e bioma dominante da região nas quais foram obtidas as amostras de solo (Benites, et al.) [7].

\begin{tabular}{ccccc}
\hline Código & Unidade & Município & Serra & Bioma dominante \\
\hline CA & Parque Nacional do Caparaó & Alto Caparaó/MG & Mantiqueira & Mata Atlântica \\
\hline CD & $\begin{array}{c}\text { Parque Nacional da } \\
\text { Chapada Diamantina }\end{array}$ & Palmeiras/BA & Espinhaço & Caatinga \\
\hline CP & Parque da Serra do Cipó & $\begin{array}{c}\text { Conceição do } \\
\text { Mato Dentro/MG }\end{array}$ & Espinhaço & Cerrado \\
\hline DI & Área de Preservação Ambiental de & Diamantina & Espinhaço & Cerrado \\
\hline IC & Parque Estadual do Itacolomi & Ouro Preto/MG & Espinhaço & Cerrado \\
\hline LT & Área de Preservação Ambiental Sul & Belo Horizonte/MG & Espinhaço & Mata Atlântica \\
\hline SB & $\begin{array}{c}\text { Parque Estadual da } \\
\text { Serra do Brigadeiro }\end{array}$ & Fervedouro/MG & Mantiqueira & Mata Atlântica \\
\hline SV & $\begin{array}{c}\text { Reserva Permanente de } \\
\text { da Mitra do Bispo }\end{array}$ & Bocaina de Minas/MG & Mantiqueira & Mata Atlântica \\
\hline IT & Parque Nacional do Itatiaia & Itamonte/MG & Mantiqueira & Cerrado/Mata Atlântica \\
\hline IB & Parque Estadual do Ibitipoca & Lima Duarte/MG & Mantiqueira &
\end{tabular}

\subsection{Titulação potenciométrica}

As titulações dos ácidos húmicos com solução padrão de $\mathrm{NaOH} 0,1 \mathrm{~mol} \mathrm{~L}^{-1} \mathrm{em} \mathrm{NaCl} 0,1 \mathrm{~mol} \mathrm{~L}^{-1}$, foram executadas em um sistema potenciométrico, baseado no potenciômetro da ORION, modelo 901, com eletrodos combinados de vidro e referência de $\mathrm{Ag} / \mathrm{AgCl}$ [8]. A adição do titulante foi feita através de um frasco de Mariotte [9] e a vazão controlada por uma válvula solenóide de teflon, sendo o volume do titulante e o $\mathrm{pH}$ da solução medidos após cada adição. Todo o sistema é controlado e os dados potenciométricos são adquiridos através de um programa desenvolvido em ambiente Windows, na linguagem Visual Basic 5.0 da Microsoft [8].

Pesou-se $0,150 \mathrm{~g}$ de ácido húmico, o qual foi solubilizado em 4,0 mL de solução padrão de $\mathrm{NaOH} 0,10 \mathrm{~mol} \mathrm{~L}^{-1}$ em $\mathrm{NaCl} 0,1 \mathrm{~mol} \mathrm{~L}^{-1}$ sob atmosfera de nitrogênio, em seguida elevou-se o volume para $25,0 \mathrm{~mL}$ com solução de $\mathrm{NaCl}$ $0,1 \mathrm{~mol} \mathrm{~L}^{-1}$; sob agitação magnética foi adicionado $\mathrm{HCl} 1 \mathrm{~mol} \mathrm{~L}^{-1}$ e/ou $\mathrm{HCl}$ mais diluído até obtenção de $\mathrm{pH}$ próximo a 2,0. Ajustado o $\mathrm{pH}$, iniciou-se a titulação com a solução padrão de $\mathrm{NaOH} 0,10 \mathrm{~mol} \mathrm{~L}^{-1}$ em $\mathrm{NaCl} \quad 0,1 \mathrm{~mol} \mathrm{~L}^{-1}$, adicionando-se o 
titulante com um incremento de $0,1 \mathrm{~mL}$ até $15,0 \mathrm{~mL}$ obtendo-se curvas de titulação com 151 pares de pontos.

As curvas de titulação foram preparadas no programa gráfico Microcal Origin 9.0 [10].

\subsection{Análise por regressão multiparamétrica não-linear}

Para o tratamento de dados potenciométricos, um programa de ajuste multiparamétrico baseado em regressão nãolinear, modificado do original, utilizado por Masini [11], foi desenvolvido na linguagem Delphi 4.0 [6].

Este programa exige o valor de $\mathrm{K}_{\mathrm{w}}$ para as condições em que foram obtidos os dados das titulações dos ácidos húmicos. Para tanto foi feita a calibração dos eletrodos combinados de vidro e referência de $\mathrm{Ag} / \mathrm{AgCl}$ através de titulação de solução padrão de $\mathrm{HCl} 0,10 \mathrm{~mol} \mathrm{~L}^{-1}$, com solução padrão de $\mathrm{NaOH} 0,10 \mathrm{~mol} \mathrm{~L}^{-1}$, seguindo o procedimento proposto por Pehrsson et al. [12], registrando-se os valores em milivolts. Com os dados da calibração obteve-se o valor de $\mathrm{K}_{\mathrm{w}}$.

\subsection{Análise das componentes principais}

O conjunto de dados obtidos para as 72 amostras constituído de 5 valores de $\mathrm{pK}_{\mathrm{a}}$ e 5 sítios ativos $\mathrm{H}^{+}$, para cada amostra, em $\mathrm{cmol}_{\mathrm{c}} \mathrm{kg}^{-1}$ dos ácidos húmicos, constituiu a matriz 72 $\mathrm{x} 10$, que foi submetida à análise das componentes principais no ambiente MatLab [14], utilizando-se o pacote PLS_Toolbox [15].

\section{Resultados e discussões}

\subsection{Titulação potenciométrica e regressão multiparamétrica não- linear}

Nas curvas de titulação obtidas é quase impossível verificar visualmente mais do que um ponto de inflexão, por se tratar de ácido com valores de $\mathrm{pK}_{\mathrm{a}}$ próximos. A figura 2 mostra a curva de titulação experimental e ajustada para uma das amostras. O procedimento foi repetido para as 72 amostras.

As curvas de titulação de substâncias húmicas são influenciadas principalmente pela presença de grupos carboxílicos, fenólicos e amínicos com diferentes valores de $\mathrm{pK}_{\mathrm{a}}$, em adição aos efeitos eletrostáticos decorrentes do acúmulo de cargas negativas com o aumento do valor de $\mathrm{pH}$. Estas curvas de titulação não apresentam pontos de inflexão bem definidos, dificultando a aplicação de métodos clássicos da primeira e segunda derivadas. Titulações levadas até um valor de $\mathrm{pH}$ préestabelecido também estão sujeitas a erros devido a ampla faixa do valor de $\mathrm{pK}_{\mathrm{a}}$ dos grupos ionizáveis [6].
Analisando os dados tratados pelo programa de regressão multiparamétrica [6] foram determinados cinco grupos tituláveis, e a partir dos valores de volumes parciais, foram calculados os percentuais de sítios ativos $\mathrm{H}^{+}$, em $\mathrm{cmol}_{\mathrm{c}} \mathrm{kg}^{-1}$ (centimol de carga por quilograma) de ácido húmico (Tabela 2), considerando que valores de $\mathrm{pK}_{\mathrm{a}}<7$, são típicos de grupamentos carboxílicos e valores de $\mathrm{pK}_{\mathrm{a}}>7$, são atribuídos a grupamentos fenólicos.

Os sítios 1, 2 e 3 referem-se a grupamentos carboxílicos com os respectivos valores de $\mathrm{cmol}_{\mathrm{c}} \mathrm{kg}^{-1}$; o somatório desses sítios, bem como o percentual destes grupamentos estão disposto como grupo 1. Da mesma forma os sítios 4 e 5 referem-se a grupamentos fenólicos com os respectivos valores de $\mathrm{cmol}_{\mathrm{c}} \mathrm{kg}^{-1}$; o somatório desses sítios, bem como o percentual destes grupamentos estão dispostos como grupo 2. Observa-se que o somatório de grupos carboxílicos é muito maior que o somatório de grupos fenólicos.

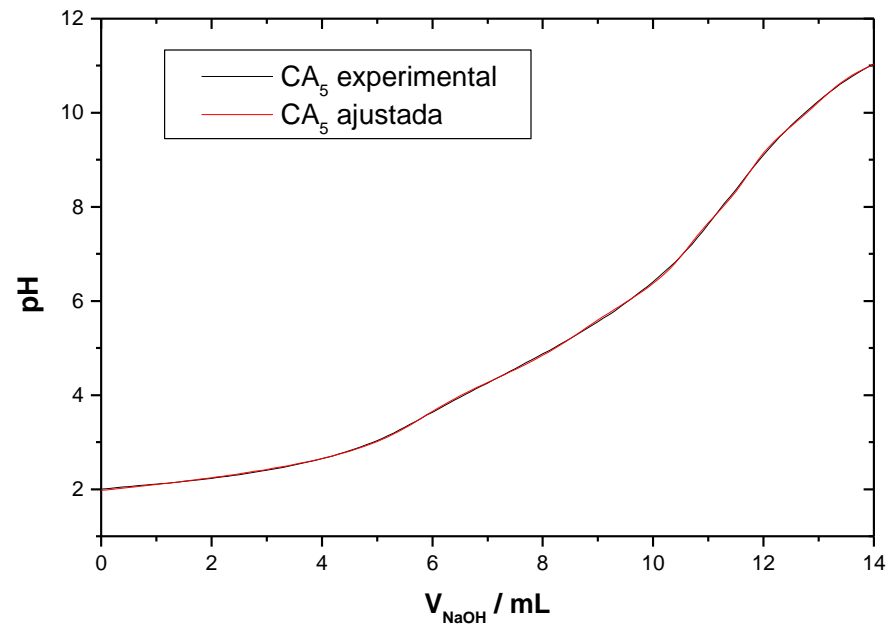

Figura 2. Exemplo de curvas de titulação experimental e ajustada de ácidos húmicos, por regressão multiparamétrica não-linear de uma das amostras do Parque Nacional do Caparaó $\left(\mathrm{CA}_{5}\right)$.

Geralmente se aceita que a carga negativa da fração orgânica seja devida à dissociação de prótons de certos grupos funcionais, principalmente de grupos carboxílicos e fenólicos. Até mesmo em $\mathrm{pH}$ menor que sete muitos grupos carboxílicos são suficientemente ácidos para se dissociarem de forma significativa, deixando uma carga negativa no grupo funcional. Quando o pH é maior que sete, mesmo os grupos carboxílicos mais fracos e fenólicos se dissociam, contribuindo para a carga negativa total da fração orgânica. Estima-se que 85 a $90 \%$ da carga negativa do húmus se devem a esses dois grupos funcionais [4]. 


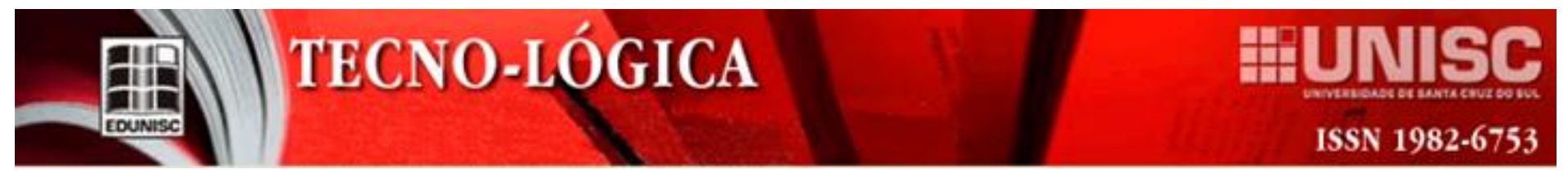

Tabela 2. Valores de sítios ativos $\mathrm{H}^{+}$, em $\mathrm{cmol}_{\mathrm{c}} \mathrm{kg}^{-1}$, dos ácidos húmicos extraídos de solo, especificando os grupos funcionais carboxílicos (Grupo 1) e fenólicos (Grupo 2 ) presentes nas amostras.

\begin{tabular}{|c|c|c|c|c|c|c|c|c|c|c|c|}
\hline \multirow[b]{2}{*}{$\mathrm{N}^{\mathrm{o}}$} & \multirow[b]{2}{*}{$\mathrm{AH}$} & \multicolumn{5}{|c|}{ Sítios ativos } & \multirow[b]{2}{*}{ Total } & \multicolumn{2}{|c|}{ Grupo 1} & \multicolumn{2}{|c|}{ Grupo 2} \\
\hline & & 1 & 2 & 3 & 4 & 5 & & $\sum$ & $\%$ & $\sum$ & $\%$ \\
\hline 1 & $\mathrm{CA}_{1}$ & 191,4 & 149,0 & 108,4 & 57,22 & 62,07 & 568,1 & 448,8 & 79,0 & 119,3 & 21,0 \\
\hline 2 & $\mathrm{CA}_{2 \mathrm{~A}}$ & 189,4 & 138,6 & 110,5 & 57,92 & 60,20 & 556,5 & 438,4 & 78,8 & 118,1 & 21,2 \\
\hline 3 & $\mathrm{CA}_{3}$ & 100,7 & 120,0 & 94,75 & 52,05 & 66,46 & 434,0 & 315,5 & 72,7 & 118,5 & 27,3 \\
\hline 4 & $\mathrm{CA}_{4}$ & 88,15 & 129,3 & 77,92 & 47,03 & 61,08 & 403,5 & 295,38 & 73,2 & 108,1 & 26,8 \\
\hline 5 & $\mathrm{CA}_{5}$ & 343,9 & 182,3 & 127,8 & 74,76 & 95,23 & 823,9 & 653,9 & 79,4 & 169,9 & 20,6 \\
\hline 6 & $\mathrm{CA}_{6}$ & 102,1 & 109,6 & 102,5 & 56,75 & 60,37 & 431,3 & 314,2 & 72,8 & 117,1 & 27,2 \\
\hline 7 & $\mathrm{CD}_{1}$ & 86,80 & 137,8 & 72,97 & 50,66 & 72,23 & 420,5 & 297,6 & 70,8 & 122.9 & 29,2 \\
\hline 8 & $\mathrm{CD}_{2}$ & 119,9 & 142,2 & 97,32 & 59,28 & 68,74 & 487,5 & 359,5 & 73,7 & 128,0 & 26,2 \\
\hline 9 & $\mathrm{CD}_{3}$ & 97,34 & 123,1 & 85,99 & 52,76 & 56,97 & 416,2 & 306,5 & 73,6 & 109,7 & 26,4 \\
\hline 10 & $\mathrm{CD}_{4}$ & 104,5 & 100,0 & 68,96 & 58,79 & 74,74 & 407,0 & 273,5 & 67,2 & 133,5 & 32,8 \\
\hline 11 & $\mathrm{CD}_{5}$ & 158,2 & 127,8 & 112,3 & 61,61 & 67,05 & 526,9 & 398,2 & 75,6 & 128,6 & 24,4 \\
\hline 12 & $\mathrm{CD}_{6}$ & 99,92 & 109,6 & 106,8 & 68,08 & 50,19 & 434,6 & 316,3 & 72,8 & 118,3 & 27,2 \\
\hline 13 & $\mathrm{CD}_{7}$ & 257,4 & 174,9 & 123,2 & 74,28 & 95,22 & 725,1 & 555,6 & 76,6 & 169,5 & 23,4 \\
\hline 14 & $\mathrm{CP}_{1}$ & 125,3 & 118,6 & 92,09 & 49,50 & 61,05 & 446,6 & 336,0 & 75,2 & 110,5 & 24,7 \\
\hline 15 & $\mathrm{CP}_{2}$ & 212,9 & 187,7 & 79,98 & 71,67 & 78,95 & 471,2 & 320,6 & 68,0 & 150,6 & 31,9 \\
\hline 16 & $\mathrm{CP}_{4}$ & 181,4 & 139,5 & 105,1 & 58,71 & 74,27 & 559,0 & 426,1 & 76,2 & 133,0 & 23,8 \\
\hline 17 & $\mathrm{CP}_{6}$ & 216,9 & 160,9 & 101,3 & 72,08 & 107,0 & 658,3 & 479,2 & 72,8 & 179,1 & 27,2 \\
\hline 18 & $\mathrm{CP}_{8}$ & 249,8 & 127,6 & 125,4 & 85,17 & 54,03 & 642,1 & 502,9 & 78,3 & 139,2 & 21,7 \\
\hline 19 & $\mathrm{CP}_{9}$ & 199,8 & 180,9 & 119,2 & 68,86 & 94,45 & 663,2 & 499,9 & 75,4 & 163,3 & 24,6 \\
\hline 20 & $\mathrm{DI}_{1}$ & 118,0 & 144,8 & 114,9 & 37,20 & 44,07 & 459,0 & 377,7 & 82,3 & 81,3 & 17,7 \\
\hline 21 & $\mathrm{DI}_{2}$ & 167,8 & 179,4 & 112,4 & 73,56 & 86,17 & 619,4 & 459,6 & 74,2 & 159,7 & 25,8 \\
\hline 22 & $\mathrm{DI}_{3 \mathrm{~A}}$ & 53,20 & 181,3 & 177,2 & 85,56 & 86,00 & 583,4 & 411,8 & 70,6 & 171,6 & 29,4 \\
\hline 23 & $\mathrm{IB}_{2}$ & 152,0 & 124,6 & 102,2 & 54,77 & 67,22 & 500,8 & 378,8 & 75,6 & 122,0 & 24,3 \\
\hline 24 & $\mathrm{IB}_{3}$ & 229,7 & 177,5 & 141,8 & 64,30 & 69,48 & 682,8 & 549,0 & 80,4 & 133,8 & 19,6 \\
\hline 25 & $\mathrm{IB}_{4}$ & 217,9 & 102,5 & 117,7 & 99,17 & 57,11 & 594,5 & 438,2 & 73,7 & 156,3 & 26,3 \\
\hline 26 & $\mathrm{IB}_{5}$ & 200,4 & 167,9 & 128,5 & 69,72 & 75,96 & 642,4 & 496,7 & 77,3 & 145,7 & 22,7 \\
\hline 27 & $\mathrm{IB}_{6}$ & 214,2 & 114,9 & 111,9 & 71,11 & 50,64 & 562,7 & 441,0 & 78,4 & 121,7 & 21,6 \\
\hline 28 & $\mathrm{IB}_{7}$ & 179,1 & 137,5 & 114,5 & 60,68 & 65,94 & 557,7 & 431,1 & 77,3 & 126,6 & 22,7 \\
\hline 29 & $\mathrm{IB}_{8 \mathrm{~B}}$ & 184,1 & 163,1 & 110,7 & 71,18 & 87,20 & 616,3 & 457,9 & 74,3 & 158,4 & 25,7 \\
\hline 30 & $\mathrm{IB}_{9 \mathrm{~A}}$ & 224,2 & 170,2 & 105,0 & 65,04 & 75,73 & 640,1 & 499,3 & 78,0 & 140,8 & 22,0 \\
\hline 31 & $\mathrm{IB}_{9 \mathrm{~B}}$ & 148,9 & 166,9 & 143,9 & 61,18 & 52,29 & 573,2 & 459,7 & 80,2 & 113,5 & 19,8 \\
\hline 32 & $\mathrm{IB}_{10 \mathrm{~A}}$ & 235,1 & 130,0 & 112,2 & 63,33 & 44,16 & 584,8 & 477,3 & 81,6 & 107,5 & 18,4 \\
\hline 33 & $\mathrm{IB}_{12 \mathrm{~A}}$ & 209,2 & 156,9 & 108,9 & 60,25 & 63,31 & 598,6 & 475,0 & 79,3 & 123,6 & 20,6 \\
\hline 34 & $\mathrm{IB}_{12 \mathrm{~B}}$ & 211,2 & 151,9 & 112,2 & 66,24 & 69,48 & 611,0 & 475,3 & 77,8 & 135,7 & 22,2 \\
\hline 35 & $\mathrm{IB}_{13 \mathrm{~B}}$ & 153,7 & 179,7 & 101,9 & 60,61 & 69,20 & 565,2 & 435,4 & 77,0 & 129,8 & 23,0 \\
\hline 36 & $\mathrm{IC}_{2 \mathrm{~A}}$ & 183,0 & 146,3 & 105,2 & 56,07 & 64,10 & 554,8 & 434,6 & 78,3 & 120,2 & 21,7 \\
\hline 37 & $\mathrm{IC}_{2 \mathrm{~B}}$ & 190,4 & 155,1 & 122,7 & 64,91 & 66,99 & 600,2 & 468,3 & 78,0 & 131,9 & 22,0 \\
\hline 38 & $\mathrm{IC}_{3}$ & 192,3 & 113,3 & 70,11 & 101,7 & 91,63 & 569,0 & 375,7 & 66,0 & 193,3 & 34,0 \\
\hline 39 & $\mathrm{IC}_{4}$ & 237,9 & 164,3 & 104,8 & 69,41 & 85,82 & 662,3 & 507,1 & 76,6 & 155,2 & 23,4 \\
\hline 40 & $\mathrm{IC}_{6}$ & 194,7 & 165,1 & 107,9 & 75,56 & 88,56 & 631,9 & 467,8 & 74,0 & 164,1 & 26,0 \\
\hline 41 & $\mathrm{IC}_{7}$ & 226,1 & 177,9 & 172,7 & 75,76 & 89,93 & 742,5 & 576,8 & 77,7 & 165,7 & 22,3 \\
\hline 42 & $\mathrm{IT}_{1}$ & 207,4 & 157,1 & 92,49 & 69,47 & 86,85 & 613,3 & 457,0 & 74,5 & 156,3 & 25,5 \\
\hline 43 & $\mathrm{IT}_{2}$ & 259,1 & 134,1 & 113,7 & 79,92 & 54,27 & 641,1 & 507,0 & 79,1 & 134,2 & 20,9 \\
\hline 44 & $\mathrm{IT}_{3}$ & 298,7 & 158,3 & 127,2 & 70,99 & 79,74 & 735,0 & 584,3 & 79,5 & 150,7 & 20,5 \\
\hline 45 & $\mathrm{IT}_{4}$ & 220,7 & 115,2 & 123,5 & 99,71 & 58,24 & 617,4 & 459,5 & 74,4 & 158,0 & 25,6 \\
\hline
\end{tabular}




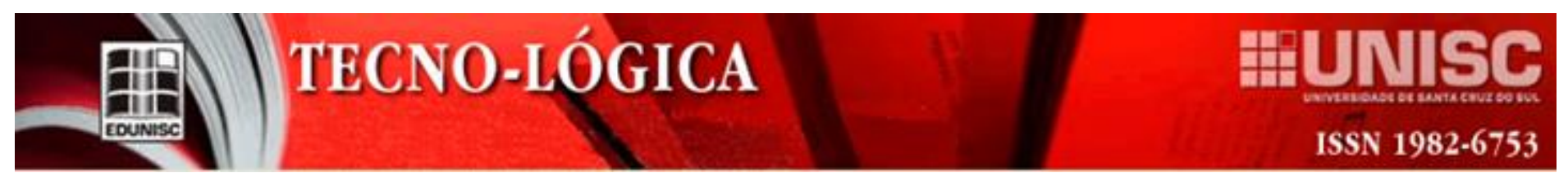

\begin{tabular}{|c|c|c|c|c|c|c|c|c|c|c|c|}
\hline \multicolumn{12}{|c|}{ (Continuação da Tabela 2.) } \\
\hline 46 & $\mathrm{IT}_{5}$ & 278,8 & 53,67 & 123,2 & 92,10 & 52,71 & 600,6 & 455,8 & 75,9 & 144,8 & 24,1 \\
\hline 47 & $\mathrm{IT}_{6}$ & 223,6 & 110,1 & 130,0 & 98,45 & 54,96 & 617,1 & 463,7 & 75,1 & 153,4 & 24,8 \\
\hline 48 & $\mathrm{IT}_{7}$ & 269,2 & 145,1 & 138,0 & 93,44 & 60,08 & 705,8 & 552,3 & 78,2 & 153,5 & 21,7 \\
\hline 49 & $\mathrm{IT}_{8}$ & 284,8 & 156,8 & 136,4 & 89,96 & 60,93 & 728,8 & 577,9 & 79,3 & 150,9 & 20,7 \\
\hline 50 & $\mathrm{LT}_{1}$ & 230,7 & 160,5 & 108,4 & 62,90 & 70,07 & 632,5 & 499,5 & 79,0 & 133,0 & 21,0 \\
\hline 51 & $\mathrm{LT}_{2}$ & 320,5 & 167,7 & 183,4 & 102,8 & 78,64 & 853,1 & 671,6 & 78,7 & 181,5 & 21,3 \\
\hline 52 & $\mathrm{LT}_{3}$ & 308,0 & 44,55 & 144,1 & 112,3 & 64,90 & 673,9 & 496,6 & 73,7 & 177,2 & 26,3 \\
\hline 53 & $\mathrm{LT}_{4}$ & 238,6 & 148,4 & 97,99 & 57,42 & 68,08 & 610,5 & 485,0 & 79,4 & 125,5 & 20,5 \\
\hline 54 & $\mathrm{LT}_{5}$ & 174,6 & 153,6 & 98,33 & 61,48 & 65,32 & 553,4 & 426,6 & 77,1 & 126,8 & 22,9 \\
\hline 55 & $\mathrm{LT}_{6}$ & 236,8 & 112,3 & 89,90 & 74,56 & 50,43 & 563,9 & 438,9 & 77,8 & 125,0 & 22,2 \\
\hline 56 & $\mathrm{LT}_{7}$ & 261,2 & 127,9 & 98,48 & 71,94 & 51,53 & 611,1 & 487,6 & 79,8 & 123,5 & 20,2 \\
\hline 57 & $\mathrm{LT}_{8}$ & 168,9 & 110,9 & 96,53 & 74,42 & 53,82 & 504,6 & 376,3 & 74,6 & 128,2 & 25,4 \\
\hline 58 & $\mathrm{SB}_{1}$ & 321,5 & 177,2 & 133,9 & 67,87 & 84,07 & 784,5 & 632,6 & 80,6 & 151,9 & 19,4 \\
\hline 59 & $\mathrm{SB}_{2}$ & 106,2 & 82,01 & 137,3 & 98,88 & 60,90 & 485,3 & 325,5 & 67,1 & 159,8 & 32,9 \\
\hline 60 & $\mathrm{SB}_{3}$ & 121,8 & 116,4 & 94,32 & 80,66 & 61,64 & 474,8 & 332,5 & 70,0 & 142,3 & 30,0 \\
\hline 61 & $\mathrm{SB}_{5}$ & 269,3 & 120,8 & 124,3 & 80,39 & 57,04 & 651,8 & 514,4 & 78,9 & 137,4 & 21,1 \\
\hline 62 & $\mathrm{SB}_{6}$ & 281,1 & 144,1 & 120,9 & 83,45 & 74,93 & 704,5 & 546,2 & 77,5 & 158,4 & 22,5 \\
\hline 63 & $\mathrm{SB}_{7}$ & 299,4 & 123,0 & 120,4 & 75,20 & 58,51 & 676,5 & 542,8 & 80,2 & 133,7 & 19,8 \\
\hline 64 & $\mathrm{SB}_{8}$ & 93,88 & 122,0 & 114,0 & 73,48 & 51,13 & 454,5 & 329,9 & 72,6 & 124,6 & 27,4 \\
\hline 65 & $\mathrm{SB}_{9 \mathrm{~A}}$ & 187,4 & 147,3 & 138,1 & 69,46 & 89,11 & 631,4 & 472,8 & 74,9 & 158,6 & 25,1 \\
\hline 66 & $\mathrm{SB}_{10}$ & 172,7 & 111,4 & 112,3 & 94,33 & 63,69 & 554,4 & 396,3 & 71,5 & 158,0 & 28,5 \\
\hline 67 & $\mathrm{SB}_{11}$ & 133,0 & 132,3 & 103,0 & 80,36 & 76,25 & 524,8 & 368,2 & 70,2 & 156,6 & 29,8 \\
\hline 68 & $\mathrm{SV}_{2}$ & 252,1 & 147,0 & 145,7 & 103,2 & 67,83 & 715,8 & 544,8 & 76,1 & 171,0 & 23,9 \\
\hline 69 & $\mathrm{SV}_{5}$ & 322,8 & 165,8 & 178,1 & 112,5 & 67,52 & 846,7 & 666,7 & 78,7 & 180,0 & 21,2 \\
\hline 70 & $\mathrm{SV}_{6}$ & 256,8 & 165,1 & 111,3 & 63,54 & 70,12 & 666,9 & 533,3 & 79,9 & 133,7 & 20,0 \\
\hline 71 & $\mathrm{SV}_{8}$ & 306,2 & 169,8 & 117,4 & 66,54 & 76,78 & 736,6 & 593,3 & 80,5 & 143,3 & 19,4 \\
\hline 72 & $\mathrm{SV}_{9}$ & 301,5 & 127,9 & 117,2 & 97,78 & 60,38 & 704,8 & 546,7 & 77,6 & 158,2 & 22,4 \\
\hline
\end{tabular}

A maior acidez dos ácidos húmicos é devida principalmente aos grupos $\mathrm{OH}$ carboxílico e fenólico que dissociam para desenvolver uma carga negativa. $\mathrm{O}$ grau a que estes grupos são ionizados ou protonados no valor do $\mathrm{pH}$ ambiental, sua abundância e distribuição influenciam a interação entre as substâncias húmicas e os solos. Assim, eles têm mais resistência à deterioração microbiológica e são os melhores agentes fixadores nos microagregados do solo.

Outra propriedade importante do ácido húmico é sua alta capacidade tampão dentro de uma larga faixa de pH. Embora sua contribuição exata à capacidade tamponante do solo não seja esclarecida totalmente, no geral, solos ricos em substâncias húmicas são bem protegidos. A análise quantitativa de interações do ácido húmico requer dados detalhados sobre: tipos, abundância e força de grupos funcionais do ácido húmico.

Tendo em vista os resultados obtidos para os cinco grupos tituláveis dos ácidos húmicos, verificou-se que são compatíveis com os resultados da literatura. A tabela 3 mostra os valores de $\mathrm{pK}_{\mathrm{a}}$ de cada grupo titulável do ácido húmico, para as 72 amostras analisadas.

\subsection{Análise das componentes principais}

A extração de informações dos resultados de um experimento químico envolve a análise de um grande número de variáveis. Algumas destas variáveis contém as informações químicas relevantes, enquanto que boa parte das variáveis adiciona pouca interpretação dos resultados em termos químicos.

A decisão sobre quais variáveis são importantes é feita, geralmente, com base na intuição química ou na experiência, ou seja, baseada em critérios que são mais subjetivos que objetivos. A redução de variáveis através de critérios objetivos, permitindo a construção de gráficos bidimensionais contendo maior informação estatística, pode ser conseguida através da análise das componentes principais [13]. 


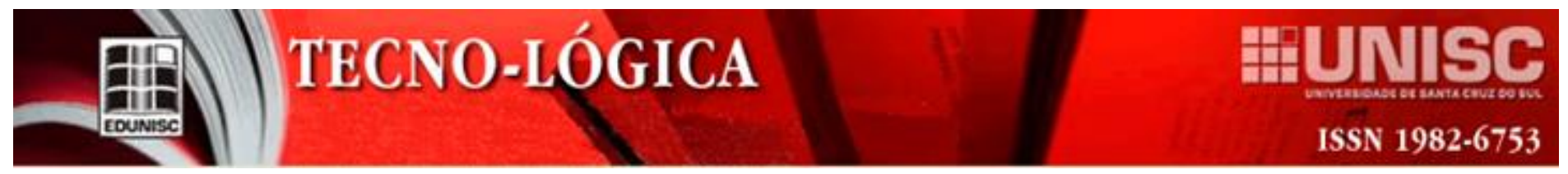

Tabela 3. Valores das constantes de ionização $\left(\mathrm{pK}_{\mathrm{a}}\right)$ correspondentes aos cinco grupos tituláveis das amostras de ácidos húmicos (AH).

\begin{tabular}{|c|c|c|c|c|c|c|c|c|c|c|c|}
\hline $\mathrm{AH}$ & $\mathrm{pK}_{\mathrm{a} 1}$ & $\mathrm{pK}_{\mathrm{a} 2}$ & $\mathrm{pK}_{\mathrm{a} 3}$ & $\mathrm{pK}_{\mathrm{a} 4}$ & $\mathrm{pK}_{\mathrm{a} 5}$ & $\mathrm{AH}$ & $\mathrm{pK}_{\mathrm{a} 1}$ & $\mathrm{pK}_{\mathrm{a} 2}$ & $\mathrm{pK}_{\mathrm{a} 3}$ & $\mathrm{pK}_{\mathrm{a} 4}$ & $\mathrm{pK}_{\mathrm{a} 5}$ \\
\hline $\mathrm{CA}_{1}$ & 2,06 & 4,20 & 5,77 & 7,62 & 9,50 & $\mathrm{IC}_{2 \mathrm{~B}}$ & 2,28 & 4,14 & 5,62 & 7,38 & 9,22 \\
\hline $\mathrm{CA}_{2 \mathrm{~A}}$ & 2,06 & 3,99 & 5,42 & 6,94 & 8,73 & $\mathrm{IC}_{3}$ & 2,67 & 4,84 & 6,85 & 9,08 & 9,11 \\
\hline $\mathrm{CA}_{3}$ & 2,56 & 4,29 & 5,89 & 7,59 & 9,36 & $\mathrm{IC}_{4}$ & 2,17 & 4,39 & 6,09 & 8,18 & 10,19 \\
\hline $\mathrm{CA}_{4}$ & 3,43 & 4,62 & 5,83 & 7,19 & 8,86 & $\mathrm{IC}_{6}$ & 2,33 & 4,56 & 6,22 & 8,25 & 10,17 \\
\hline $\mathrm{CA}_{5}$ & 2,07 & 4,35 & 5,99 & 7,85 & 9,73 & $\mathrm{IC}_{7}$ & 2,36 & 4,41 & 5,98 & 7,88 & 9,82 \\
\hline $\mathrm{CA}_{6}$ & 3,22 & 4,39 & 5,58 & 7,05 & 8,83 & $\mathrm{IT}_{1}$ & 2,25 & 4,33 & 6,09 & 8,14 & 10,08 \\
\hline $\mathrm{CD}_{1}$ & 3,57 & 4,88 & 6,07 & 7,42 & 9,04 & $\mathrm{IT}_{2}$ & 2,02 & 3,81 & 4,96 & 6,12 & 7,60 \\
\hline $\mathrm{CD}_{2}$ & 2,26 & 4,27 & 5,88 & 7,75 & 9,56 & $\mathrm{IT}_{3}$ & 2,04 & 4,16 & 5,74 & 7,62 & 9,52 \\
\hline $\mathrm{CD}_{3}$ & 2,82 & 4,37 & 5,96 & 7,83 & 9,47 & $\mathrm{IT}_{4}$ & 2,12 & 3,69 & 4,73 & 5,89 & 7,34 \\
\hline $\mathrm{CD}_{4}$ & 3,70 & 5,01 & 6,41 & 8,11 & 9,76 & $\mathrm{IT}_{5}$ & 1,90 & 3,47 & 4,29 & 5,65 & 7,18 \\
\hline $\mathrm{CD}_{5}$ & 2,35 & 4,14 & 5,49 & 6,95 & 8,80 & $\mathrm{IT}_{6}$ & 2,14 & 3,74 & 4,77 & 5,97 & 7,46 \\
\hline $\mathrm{CD}_{6}$ & 2,38 & 3,96 & 5,17 & 6,18 & 7,38 & $\mathrm{IT}_{7}$ & 1,96 & 3,74 & 4,91 & 6,11 & 7,61 \\
\hline $\mathrm{CD}_{7}$ & 2,07 & 4,27 & 5,91 & 7,84 & 9,72 & $\mathrm{IT}_{8}$ & 1,90 & 3,83 & 5,02 & 6,25 & 7,79 \\
\hline $\mathrm{CP}_{1}$ & 2,06 & 4,04 & 5,47 & 6,92 & 8,66 & $\mathrm{LT}_{1}$ & 2,15 & 4,24 & 5,83 & 7,77 & 9,58 \\
\hline $\mathrm{CP}_{2}$ & 2,41 & 4,26 & 5,76 & 7,45 & 9,32 & $\mathrm{LT}_{2}$ & 1,96 & 3,94 & 5,16 & 6,51 & 8,13 \\
\hline $\mathrm{CP}_{4}$ & 2,13 & 4,19 & 5,68 & 7,35 & 9,06 & $\mathrm{LT}_{3}$ & 1,93 & 3,41 & 4,29 & 5,72 & 7,40 \\
\hline $\mathrm{CP}_{6}$ & 2,24 & 4,40 & 6,17 & 8,28 & 10,34 & $\mathrm{LT}_{4}$ & 2,09 & 4,29 & 5,91 & 7,82 & 9,61 \\
\hline $\mathrm{CP}_{8}$ & 1,98 & 3,92 & 5,14 & 6,34 & 7,74 & $\mathrm{LT}_{5}$ & 2,39 & 4,33 & 5,91 & 7,83 & 9,61 \\
\hline $\mathrm{CP}_{9}$ & 2,47 & 4,42 & 6,15 & 8,16 & 10,12 & $\mathrm{LT}_{6}$ & 2,06 & 4,06 & 5,31 & 6,33 & 7,58 \\
\hline $\mathrm{DI}_{1}$ & 2,98 & 4,47 & 5,71 & 6,76 & 7,73 & $\mathrm{LT}_{7}$ & 2,05 & 4,12 & 5,29 & 6,38 & 7,70 \\
\hline $\mathrm{DI}_{2}$ & 2,60 & 4,47 & 6,10 & 8,16 & 10,07 & $\mathrm{LT}_{8}$ & 2,15 & 3,98 & 5,00 & 6,13 & 7,55 \\
\hline $\mathrm{DI}_{3 \mathrm{~A}}$ & 2,93 & 3,93 & 4,94 & 7,05 & 9,32 & $\mathrm{SB}_{1}$ & 2,10 & 4,36 & 6,01 & 7,91 & 9,70 \\
\hline $\mathrm{IB}_{2}$ & 2,00 & 4,08 & 5,53 & 7,07 & 8,79 & $\mathrm{SB}_{2}$ & 1,90 & 2,89 & 4,32 & 5,77 & 7,36 \\
\hline $\mathrm{IB}_{3}$ & 2,29 & 4,23 & 5,78 & 7,62 & 9,49 & $\mathrm{SB}_{3}$ & 2,34 & 3,83 & 4,87 & 6,06 & 7,54 \\
\hline $\mathrm{IB}_{4}$ & 2,02 & 3,75 & 4,81 & 5,98 & 7,41 & $\mathrm{SB}_{5}$ & 2,02 & 4,00 & 5,22 & 6,45 & 7,82 \\
\hline $\mathrm{IB}_{5}$ & 2,26 & 4,29 & 5,86 & 7,74 & 9,59 & $\mathrm{SB}_{6}$ & 2,01 & 3,98 & 5,23 & 6,50 & 7,99 \\
\hline $\mathrm{IB}_{6}$ & 2,05 & 3,93 & 5,11 & 6,19 & 7,50 & $\mathrm{SB}_{7}$ & 2,01 & 4,01 & 5,22 & 6,44 & 7,83 \\
\hline $\mathrm{IB}_{7}$ & 2,32 & 4,30 & 5,87 & 7,79 & 9,54 & $\mathrm{SB}_{8}$ & 1,91 & 3,82 & 5,14 & 6,31 & 7,64 \\
\hline $\mathrm{IB}_{8 \mathrm{~B}}$ & 2,63 & 4,59 & 6,23 & 8,24 & 10,11 & $\mathrm{SB}_{9 \mathrm{~A}}$ & 2,39 & 4,48 & 6,23 & 8,04 & 9,80 \\
\hline $\mathrm{IB}_{9 \mathrm{~A}}$ & 2,35 & 4,38 & 6,09 & 8,21 & 10,27 & $\mathrm{SB}_{10}$ & 2,22 & 3,88 & 4,90 & 6,15 & 7,63 \\
\hline $\mathrm{IB}_{9 \mathrm{~B}}$ & 2,52 & 4,16 & 5,52 & 6,99 & 8,84 & $\mathrm{SB}_{11}$ & 3,16 & 4,93 & 6,76 & 8,80 & 10,09 \\
\hline $\mathrm{IB}_{10 \mathrm{~A}}$ & 2,06 & 3,90 & 5,09 & 6,19 & 7,40 & $\mathrm{SV}_{2}$ & 2,14 & 3,86 & 5,07 & 6,35 & 7,91 \\
\hline $\mathrm{IB}_{12 \mathrm{~A}}$ & 2,25 & 4,26 & 5,84 & 7,73 & 9,52 & $\mathrm{SV}_{5}$ & 2,04 & 3,84 & 5,04 & 6,40 & 8,05 \\
\hline $\mathrm{IB}_{12 \mathrm{~B}}$ & 2,19 & 4,23 & 5,80 & 7,70 & 9,52 & $\mathrm{SV}_{6}$ & 2,27 & 4,30 & 5,93 & 7,77 & 9,51 \\
\hline $\mathrm{IB}_{13 \mathrm{~B}}$ & 2,35 & 4,26 & 5,84 & 7,69 & 9,50 & $\mathrm{SV}_{8}$ & 2,16 & 4,27 & 5,89 & 7,75 & 9,59 \\
\hline $\mathrm{IC}_{2 \mathrm{~A}}$ & 2,23 & 4,14 & 5,58 & 7,15 & 8,92 & $\mathrm{SV}_{9}$ & 1,90 & 3,79 & 4,81 & 5,99 & 7,50 \\
\hline
\end{tabular}

Os resultados da análise das componentes principais estão representados em espaço de duas dimensões, como mostrado na tabela 4 e nas figuras 3, 4, 5 e 6 . Estes dados foram auto escalonados e as quatro primeiras componentes principais explicam $91,23 \%$ da variância, sendo $53,43 \%$ explicados pela primeira componente $(\mathrm{CP} 1), 22,93 \%$ pela segunda componente (CP2), $7,79 \%$ pela terceira componente (CP3) e 7,07\% pela quarta componente (CP4).

As figuras 3 e 4 mostram a separação das amostras considerando a influências das variáveis $\mathrm{pK}_{\mathrm{a}}$ e sítios ativos $\mathrm{H}^{+}$. 
Tabela 4. Variâncias (autovalores) obtidas para as 4 primeiras componentes principais

\begin{tabular}{cccc}
\hline Componente & Autovalor & $\begin{array}{c}\text { Porcentagem } \\
\%\end{array}$ & $\begin{array}{c}\text { Acumulado } \\
\%\end{array}$ \\
\hline CP1 & 5,34 & 53,43 & 53,43 \\
\hline CP2 & 2,29 & 22,93 & 76,37 \\
\hline CP3 & 0,779 & 7,79 & 84,16 \\
\hline CP4 & 0,707 & 7,07 & 91,23 \\
\hline
\end{tabular}

No gráfico dos escores (Figura 3) entre a CP1 e CP2, pode-se observar que para valores negativos da CP1 encontramse amostras da Serra da Mantiqueira onde predominantemente se tem o bioma de Mata Atlântica. No entanto, aparece junto a essas amostras as que se encontram no bioma Cerrado (LT2, LT3, CP8, LT7, CP1, LT6 e LT8) e no bioma Caatinga (CD6). Estas amostras tem a influência das variáveis dos sítios ativos (SA1, SA3 e SA4), como é mostrado no gráfico dos pesos em relação às duas primeiras componentes na figura 4.
Considerando valores positivos da CP1 encontram-se amostras da Serra do Espinhaço e a maioria das amostras da Serra da Mantiqueira oriunda do bioma da Mata Atlântica no município do Alto Caparaó (MG). Nesta região da CP1, apenas a amostra CD6 do bioma de Caatinga não se encontra localizada na mesma, mostrando que as demais possuem um comportamento que as diferenciam.

Em relação a $\mathrm{CP} 2$, os valores negativos encontram-se amostras do bioma mata Atlântica, Cerrado e Cerrado / Mata Atlântica. Sendo que as amostras do bioma Caatinga em sua maioria encontram-se nesta separação pela $\mathrm{CP} 2$, apenas a amostra CD7 deste bioma encontra-se na CP2 positiva. Nesta região da $\mathrm{CP} 2$ positiva localizam-se as amostras dos biomas Cerrado e mata Atlântica. Na separação das amostras nota-se pelo gráfico dos pesos, figura 4, que a localização na região negativa da CP2 é influenciada principalmente pelas variáveis $\mathrm{pK}_{1}$ e $\mathrm{pK}_{2}$, as amostras que se encontram na região positiva são influenciadas pelas demais variáveis $\left(\mathrm{pK}_{3}, \mathrm{pK}_{4}, \mathrm{pK}_{5}, \mathrm{SA} 1, \mathrm{SA} 2\right.$, SA3, SA4 e SA5).

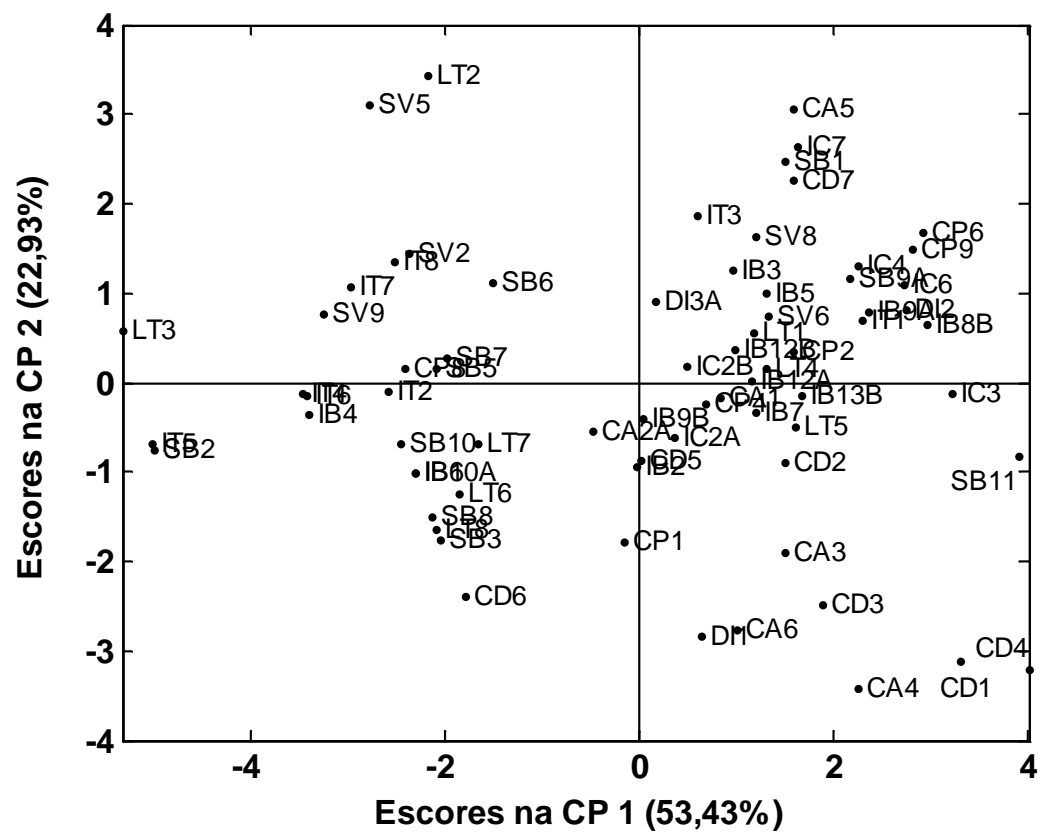

Figura 3.Gráfico dos escores das componentes principais CP1 vs. CP2 para os dados potenciométricos das 72 amostras. 

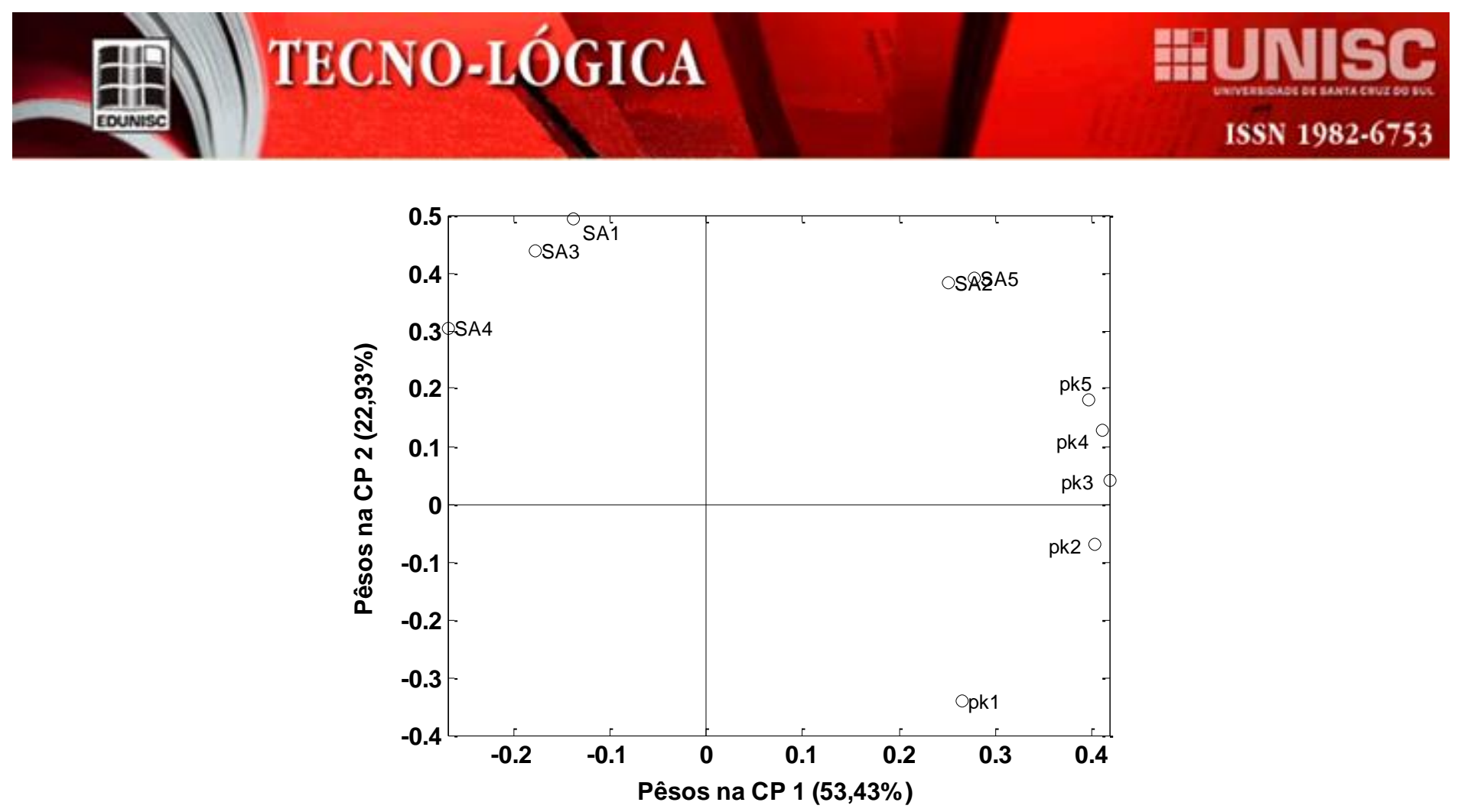

Figura 4.Gráfico dos pesos das variáveis nas componentes principais, $\mathrm{CP} 1 \mathrm{vs.} \mathrm{CP} 2$, considerando as 10 variáveis, sendo 5 valores de $\mathrm{pK}_{\mathrm{a}} \mathrm{e} 5$ valores de sítios ativos $\mathrm{H}^{+}$.

Estabelecendo a relação entre a CP1 e CP3 (figura 5), a CP1 apresenta a mesma separação para as amostras na figura 3. Sendo que, o mesmo acontece para as influências das variáveis SA1, SA3 e SA4 para amostras na CP1 negativa e as demais para as amostras na CP1 positiva. No entanto, para a CP3 o comportamento é diferente, sendo que, na $\mathrm{CP} 3$ negativa encontram-se praticamente as amostras descritas pela CP2 negativa e na CP3 positiva encontram-se praticamente as amostras descritas na CP2 positiva. A diferença nesta componente $(\mathrm{CP} 3)$ se nota pela influência das variáveis. Na CP3 negativa a influência é descrita pelas variáveis $\mathrm{SA} 1, \mathrm{SA} 2, \mathrm{pK}_{3}$, $\mathrm{pK}_{4}$ e $\mathrm{pK}_{5}$, já na $\mathrm{CP} 3$ positiva a influência é descrita pelas variáveis $\mathrm{SA} 3, \mathrm{SA} 4, \mathrm{SA} 5, \mathrm{pK}_{1}$ e $\mathrm{pK}_{2}$.

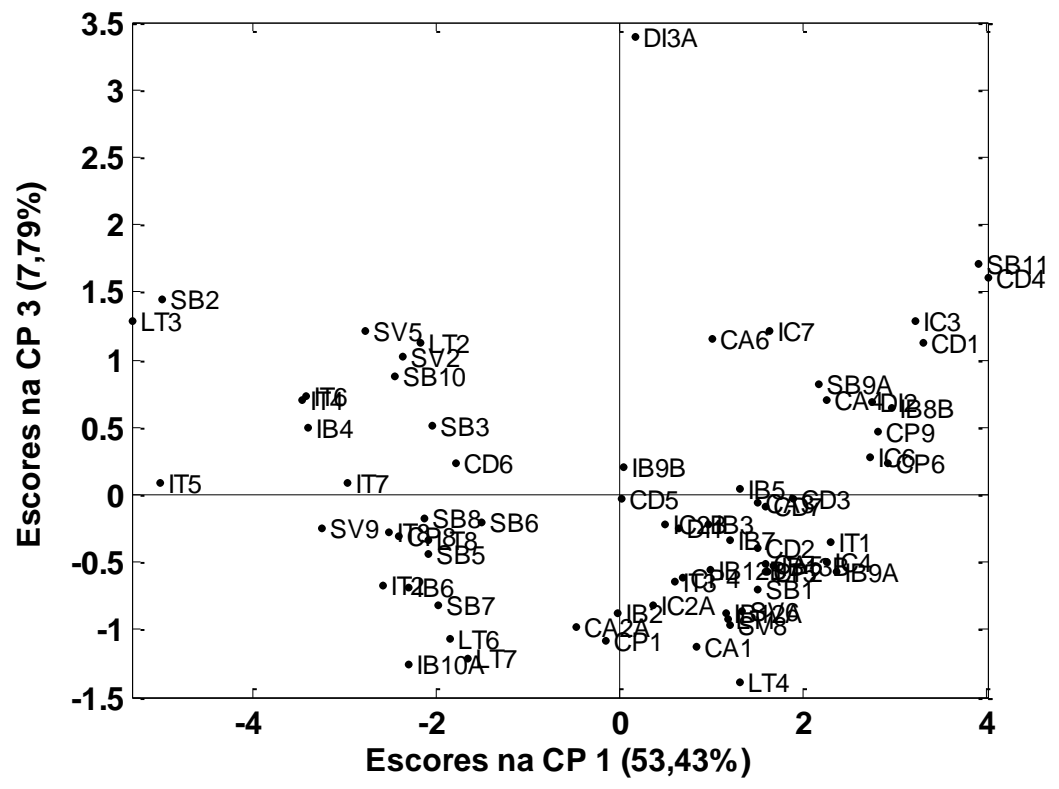

Figura 5. Gráfico dos escores nas componentes principais, CP1 vs.CP3 para os dados potenciométricos e sítios ativos $\mathrm{H}^{+}$das 72 amostras. 

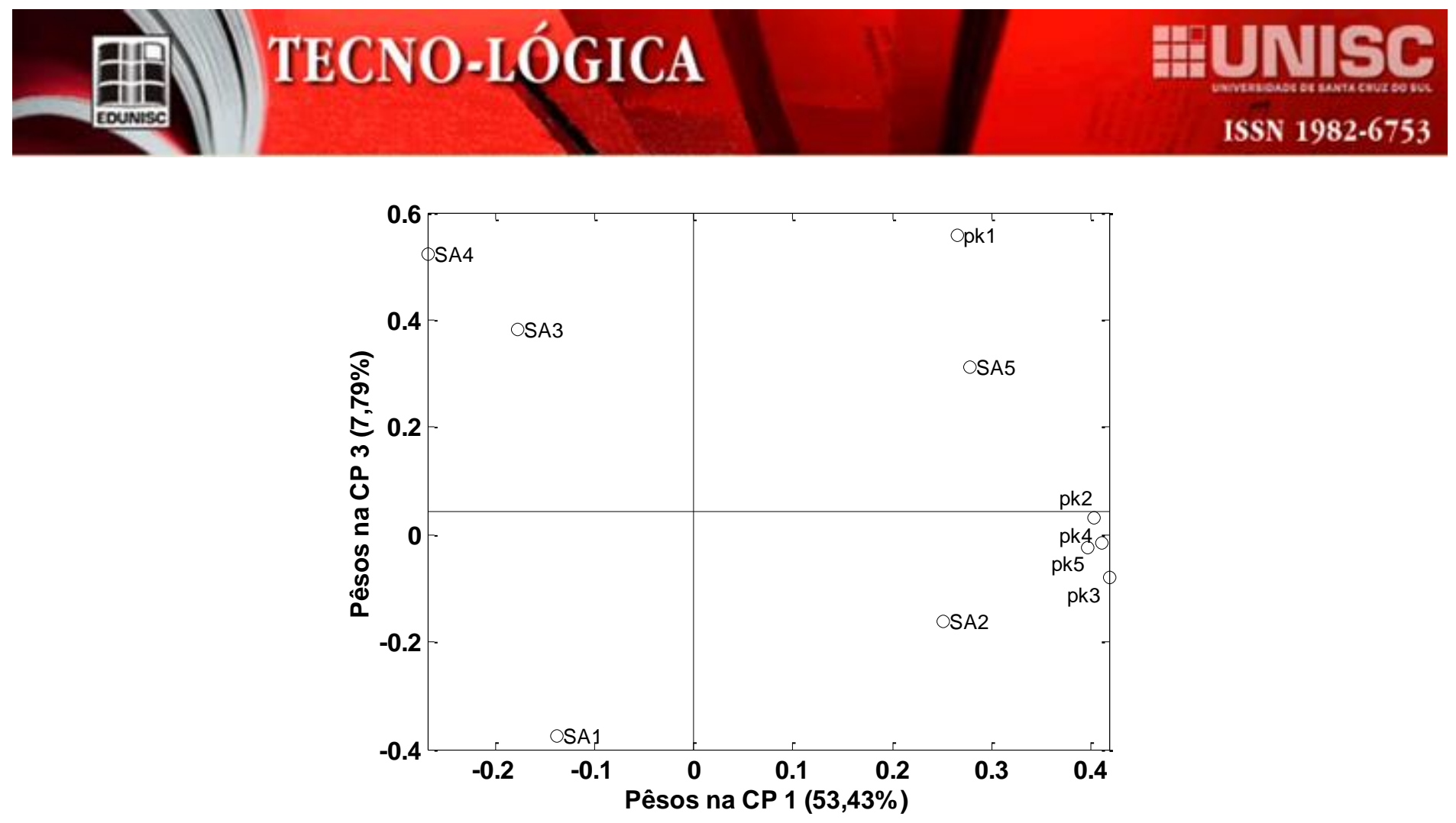

Figura 6. Gráfico dos pesos das variáveis nas componentes principais, CP1 vs. CP3, considerando as 10 variáveis sendo 5 valores de $\mathrm{pK}_{\mathrm{a}}$ e 5 valores de sítios ativos $\mathrm{H}^{+}$.

\section{Conclusões}

As amostras coletadas nos biomas Cerrado e Mata Atlântica em diferentes regiões, apresentaram separações influenciadas pelas variáveis de $\mathrm{pK}_{\mathrm{a}}$ e valores de sítios ativos $\mathrm{H}^{+}$.

Sendo que, esta separação ocorre a nível de componentes principais (CP1 vs. CP2 e CP1 vs CP3), desta forma a separação na primeira componente principal ocorre em função dos valores de sítios ativos $\mathrm{H}^{+}$, já na segunda e terceira componentes principais os valores de $\mathrm{pK}_{\mathrm{a}}$ tem maior influência, mostrando que os sítios ativos 1, 3 e 4, sempre se encontram mais próximos no gráfico dos pesos, em função de valores da maioria das amostras localizadas nesta região das componente principais.

Os valores de $\mathrm{pK}_{\mathrm{a}}$ maiores $\left(\mathrm{pK}_{3}, \mathrm{pK}_{4} \mathrm{e} \mathrm{pK}_{5}\right)$ tem maiores influências na separação das amostras de acordo com a segunda componente principal. Assim, um dos biomas que mais se destaca na separação influenciado por essas variáveis é o de Caatinga (CD), que tem sua maior concentração de amostras na região positiva da primeira componente principal.

\section{Agradecimentos}

Os autores agradecem à Fundação de Apoio à Pesquisa do Estado de Minas Gerais - FAPEMIG, pelo apoio financeiro concedido para a realização deste projeto.

\section{POTENTIOMETRIC CHARACTERIZATION AND RECOGNITION OF HUMIC ACID PATTERNS EXTRACTED FROM ALTITUDE SOILS}

ABSTRACT: High altitude rock-vegetation is found at the top of highest mountains in Brazil such as Espinhaço and Mantiqueira complexes at Minas Gerais and Bahia states consisting in ecosystems with outstanding characteristics in diversity of flora and fauna. The soil in these areas is generally shallow, poor in nutrients, but rich in exchangeable iron and aluminum. The characterization of humic acids from such ecosystems among other chemical components is very useful to understand the fundamental properties of the organic composition of the soil. A total of 72 soil samples from 10 different locations in the Espinhaço and Mantiqueira complexes were potentiometrically characterized. The data of the potentiometric titrations were processed in a software based on the Delphi language, in order to obtain the ionization constants and the percentages of the titrated groups. This software proved to be efficient in the reproduction of the titration curves with a notable agreement with the experimental ones. After processing the potentiometric data, the values of the ionization constants and percentages of the carboxylic and phenolic groups were subjected to the principal components analysis in the MatLab environment, using a matrix of 72 samples and 10 variables, obtaining a model in which it was found that the first four principal components explained $91.23 \%$ of the total variation of the original data. The 
characteristics of humic acids evidenced by the potentiometric titration reflect the conditions in which these acids were formed, although not allowing a more effective separation between the groups evidenced by the principal components analysis.

Keywords: High altitude soils. Humic acids. Potentiometric titration. Principal component analysis.

\section{Referências}

1. STEVENSON, F. J. Humus chemistry. New York: Wiley, 1982. 443p.

2. BENITES, V. M.; MENDONÇA, E. S.; SCHAEFER, C. E. G.; NOVOTNY, E. H.; REIS, E. L.; KER, J. C. Properties of black soil humic acids from high altitude rocky complexes in Brazil. Geoderma, 127, 104-113, 2005.

3. SANTISTEBAN, A. J.; SOUZA, S. M.; LANDGRAF, M. D.; REZENDE, M. O. Estudo das características físico-químicas do ácido húmico de vermicomposto. In: $2^{\mathrm{O}}$. ENCONTRO BRASILEIRO DE SUBSTÂNCIAS HÚMICAS, São Carlos, 1997. Anais... São Carlos: CNPDIA, p.129, 1997.

4. SCHULTEN, H. R., SCHNITZER, M. Chemical model structures for soil organic matter and soils. Soil Science, 162, 115-130, 1997.

5. LINDBERG, W.; KOWALSKI, B. Evaluation of potentiometric acid-base titration by partial-least-squares calibration. Analytica Chimica Acta, 206, 125-135, 1988.

6. REIS, C. D. G.; FONSECA, R. A. D.; REIS, E. L.; REIS, C.; BRIGHENTI, C. R. G.; MATIAS, A. A. Programa de ajuste multiparamétrico de curvas de titulação potenciométricas de ácidos húmicos. Revista Brasileira de Ciência do Solo, 34, 569-573, 2010.

7. BENITES, V. M., MADARI, B. AND MACHADO, P. L. O. A., Extração e fracionamento quantitativo de substâncias húmicas do solo: Um procedimento simplificado de baixo custo. Embrapa Solos. Comunicado Técnico, 16, p.7, Rio de Janeiro, 2003.

8. BARBOSA, L. C. DE ALMEIDA; MALTHA, C. R. Á.; DEMUNER, A. J. ; CAZAL, C. M. ; REIS, E. L. ; COLODETTE, J. L.A Rapid Method for Quantification of Carboxyl Groups in Cellulose Pulp. Bioresources, 8, 10431054, 2013.

9. LYNCH, J. A.; NARRAMORE, J. D. The Mariotte bottle and automation of a potentiometric titration. Journal of Chemical Education, 67, 6, 533-535, 1990.

10. MICROCAL, Origin 9.0, Microcal, Northampton, MA, 2010.

11. MASINI, J. C. Caracterização Ácido-Base da Superfície de Espécies Mistas da Alga Spirulina Através de Titulação Potenciométrica e modelo de distribuição de sítios discretos. Química Nova, 22, 5, 679-683, 1999.

12. PEHRSSON, L., INGMAN, F., JOHANSSON, A. Acid-base titrations by stepwise additions of equal volumes of titrant with special reference to automatic titrations. 1. theory, discussion of gran functions, hofstee method and 2 proposed methods for calculating equivalence volumes. Talanta, 23, 769-780, 1976.

13. SILVA, L. O. C.; REIS, E. L. FIDÊNCIO, P. H.; REIS, C.; PEREIRA, F. M.; NUNES, L. C. Aplicação da Análise de Componentes Principais no Estudo da Voltametria Adsortiva de Íons Metálicos. Tecno-Lógica, 13, 103-108, 2009.

14. MATH WORKS, Matlab, MathWorks, Natick, MA, 1993.
15. PLS_Toobox. 2019.

Disponível https://www.mathworks.com/products/connections/product_detail/plstoolbox.html, Acesso em: 05/11/2019. em: 